\title{
3. Managing Major Programs and Projects: A View From the Boardroom
}

\section{Christina Gillies, Non Executive Director and IT Governance Consultant}

I sit on a number of boards, including public, private, and not-for-profit, and I can assure you every one is different, however the debate around IT is common to all, and revolves around the question: 'How do we get a grip on this critical corporate asset that has become an integral part of most businesses and government agencies?'

The consequences of project and operational failure can bring a company to its knees, yet in the boardroom we often feel like powerless onlookers rather than informed participants.

We are spending an ever-increasing amount of money on IT and the size of the loss gets bigger every time an IT investment goes wrong. In addition, the demands of privacy legislation and compliance surrounding IT and information security are becoming more and more complex.

The incidence of IT failure continues to grow. Some incidents have had high profile, but many failures in small to medium enterprises cause equal damage with little publicity. However, as a result, we find the attention of regulatory bodies and shareholders clearly focused on what goes on behind Boardroom doors and on the accountabilities of business, audit and finance.

Most board would agree that IT should now be on the agenda, the question is once it is on the agenda, what do we do with it?

For the most part, boards get to understand that a project has problems or is completely off the rails when the damage has been done.

Why? Did the board know about the project? Did we understand the risks? Did we have sufficient information? If we had information, did we understand it?

Today I would like to talk from a boardroom perspective about:

- the relationship between the board and the project;

- IT governance and how it applies to projects; and

- how Boards can realistically get reasonable oversight of IT and know that the company is getting the planned return on investment and risk is being managed.

First, I think it is important that we start with a common view of the boardroom. A board meets formally between six and twelve times a year. Meetings are 
scheduled to deal with a wide range of corporate governance tasks which range through setting and monitoring strategic direction, monitoring operational performance, financial management, regulatory and compliance issues, shareholder and analyst expectation, compliance with regulatory bodies, internal and external audit, risk management, international reporting standards, Sarbanes Oxley ${ }^{l}$... the list goes on.

The board has a lot on its plate, so projects that come to the board tend not to get a lot of air time once approved

\section{The project scene from a Board perspective}

Most big spend projects come to the board for approval and are normally accompanied by a well thought out presentation outlining strategic fit, costs and benefits. After long and considered debate the project will most likely be approved, with the board indicating the need for progress reports against budget and plan. Reporting at regular intervals commences and here is where the frustration starts, reports go from 'on time on budget to 'slippage with good reason'.

\section{We have a problem}

Boards are required to act in the event of either a huge failure on implementation, or a big delay in implementation causing significant business losses. The investigations commence, no doubt you have all watched or participated. The disturbing fact is the accountable parties are often difficult to identify and the reasons for failure are many and varied.

In the boardroom, the debate goes on about what to do differently and how to avoid repeat scenarios.

The key questions that need to be asked are:

- Who was accountable?

- Were post mortems conducted to identify source(s) of failure?

- Do we have consultant reviews and recommendations?

- Could the problem have been avoided?

- Did the board do its job?

\section{What can be done differently?}

Starting in the boardroom, if consultants were engaged to identify some of the problematic issues and behaviours in the boardroom around the treatment of projects, they might come up with a list that looks something like this:

- the board often make decisions in isolation due to lack of context for informed debate;

- the board treats project approval as an event - without strategic context; 
- the board relies on the capability of the CIO rather than ensuring good governance is in place;

- the board holds the CIO accountable for the failure of business projects;

- the board digs into detail and misses the big picture;

- project risk monitoring can get lost in the overall risk profile of the organisation; and

- IT is not home ground for most, so the subject can get passed by very quickly.

So what is the answer? What does the board do? The simple answers include:

- implement better IT governance;

- know what questions to ask; or

- apply better project governance.

These sound good, but what do they really mean? And more importantly, will these measures address the problem?

In isolation, I suspect not: in the first place the board has to understand what it is governing! The answer lies in:

- implementing better IT governance in the boardroom;

- knowing what questions to ask; and

- implementing better project governance.

Before we look at the scope of IT governance, let's go back to first principles, derived from the ASX principles of Corporate Governance. The key phrases to note are:

- 'provide accountability and control systems commensurate with the risks involved'; and

- 'accountabilities, processes and auditable and measurable control'.

This raises questions about what we look at in the boardroom: Gantt charts or decision frameworks and accountabilities? 


\section{What is the Board's role?}

The Board is ultimately accountable for the company's purpose and the means of delivering it ... and the Board is accountable for the Governance of the organisation:

- 'Good corporate governance structures encourage companies to create value and provide accountability and control systems commensurate with the risks involved'.

- 'Governance is a set of accountabilities, processes, and auditable and measurable controls that ensure a company is on track to achieve its objectives'.

ASX Principles of Corporate Governance ${ }^{2}$

Broadbent and Weill developed a further definition which clarifies IT governance specifically. The key words here being 'IT governance is different from IT management'. Think about who makes the project decisions in your organisation and who is accountable for implementing them.

\section{IT Governance}

- IT governance is about who is entitled to make major decisions, who has input and who is accountable for implementing those decisions.

AND

- $\quad$ IT governance is different from IT management.

(Broadbent and Weill, 2003; Weill and Ross 2004.)

Broadbent and Weill also recommend that we start in the Boardroom by treating IT as we would treat any other corporate asset and apply the same rigor. For IT this would mean the Board decides strategic direction, ensures accountability, makes policy and monitors and supervises. The board appoints the CEO and the CEO and the board appoints the senior executive team and they are accountable for the management of the company's key assets, including IT.

I think this is where the answer lies for boards in coming to grips with IT - it is not about project detail and Gantt charts - it about decision making, accountabilities and processes (see Fig 1). 


\section{Figure 1}

Begin by treating your IT assets like any other assets...

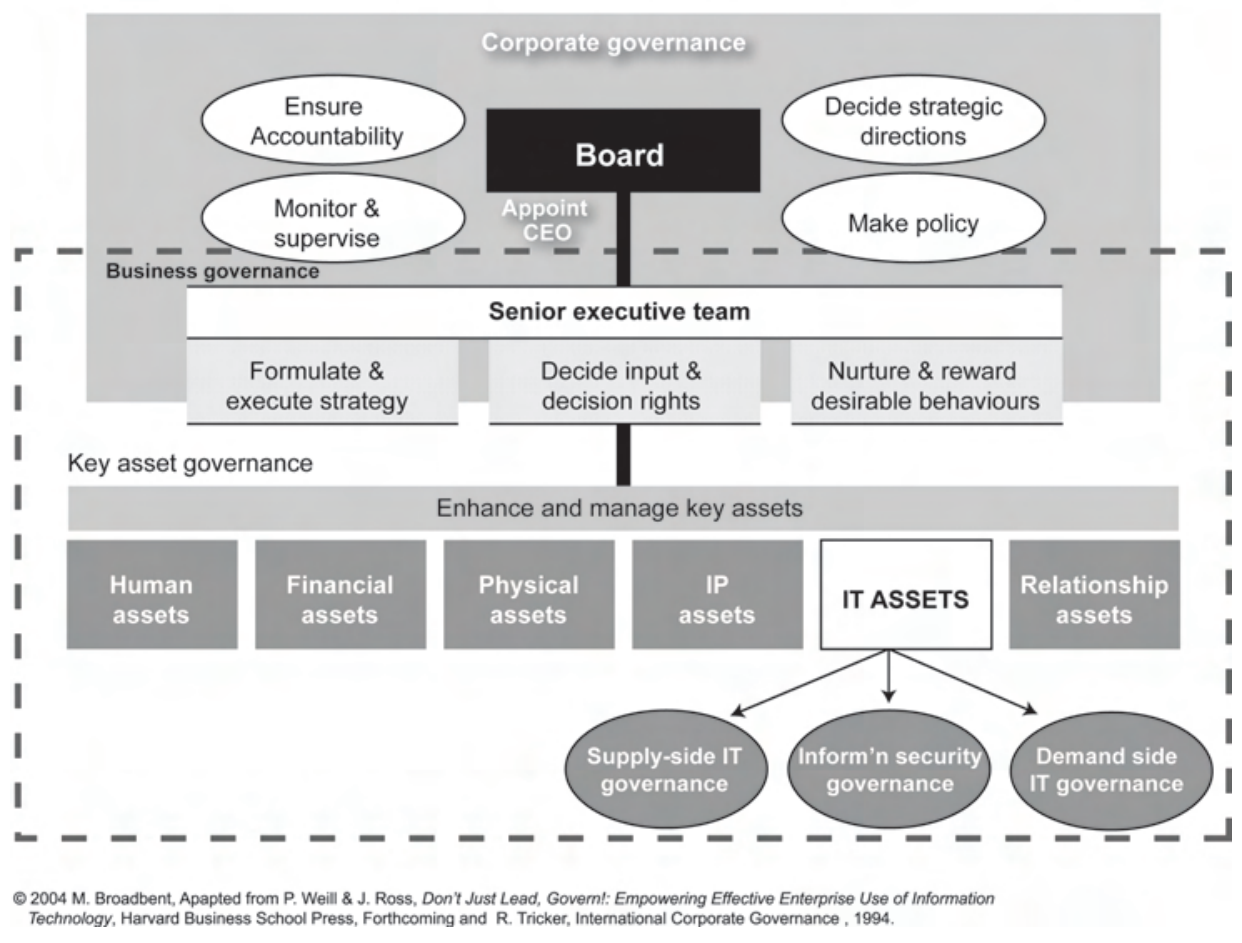

\section{The Finance analogy is a good one}

Boards spend a lot of time on financial governance, regulation and compliance and the board along with the auditors; ensure that the accountability structures and processes are in place throughout the organisation to deliver accurate and reliable financial information to the shareholders and stakeholders.

The question is, 'why do we treat IT any differently?'. It would be reasonable to assume that we could have processes and accountabilities in place for the accurate and reliable delivery of IT projects and ongoing operations that can be are easily monitored and audited.

As an asset class, IT is new territory for boards - finance is an age old profession and we can apply many of its disciplines to establish good IT governance practices.

IT governance often gets confused with IT management and the CIO gets to be accountable for anything that has the word IT attached to it. As a consequence the business ends up being interested onlookers and expert critics, rather than accountable participants in any business process pertaining to IT. 


\section{IT governance includes the Board, the Business and IT}

Analysis of many project failures shows that the business parties either did not understand or accept their role, and IT tried to fill in the gap. In a vacuum IT will make the decisions.

Most projects are business projects and over 60 per cent of the work is non-technical IT work, requiring business skills and knowledge such as process design, organisational change, benefits identification, product development, change management and training. As a rule of thumb, well over half of IT project costs are in the business. IT is the enabler, not the driver,

\section{What does it mean from a governance perspective?}

Let's work our way through 'who makes decisions' and 'who is accountable for what' through the lifecycle of a project from concept to outcome. It starts in the Boardroom where the Board, with the $\mathrm{CEO}$ and executive, sets strategic direction.

The interaction between business and IT delivers the Business IT Strategic Plan which outlines the key initiatives the company will implement over the next 'strategic' period. These initiatives will be converted into projects through the annual business planning process (see Fig 2).

\section{Figure 2}

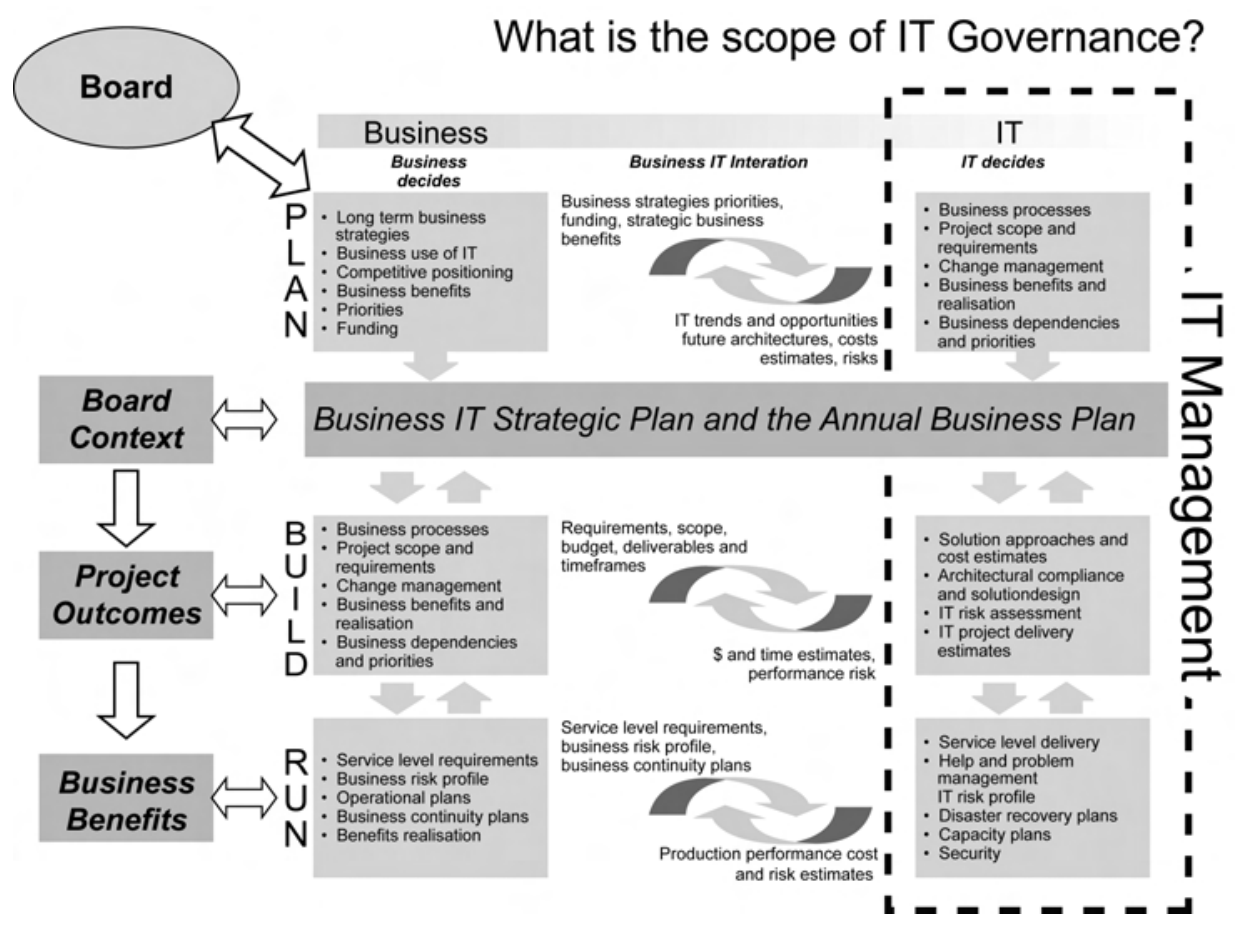


In the boardroom, the longer term Business IT Strategic Plan and the Annual Plans are key. The plans are the roadmap for the Board. The plans set the criteria for Board decision-making and the framework for board focus, monitoring and measurement.

The board needs to be confident that governance structures (clear accountabilities and decision making frameworks) are in place throughout the life cycle and that the board focuses on the project outcomes and delivered benefits rather than specific project progress.

The bottom line is that, IT governance is not IT management and IT governance is not just inside the IT department.

IT accountabilities and processes cross all organisational boundaries and, from a Board perspective, we need to know that these processes and accountabilities are in place and are being rigorously monitored.

\section{Nota bene!}

- There is a business decision behind every IT Decision;

AND

- Business must be held accountable for these decisions.

Finally, in the context of IT governance, it is appropriate to talk about the relationship between projects and the board. We tend to put huge emphasis on getting IT Project Management right and project governance right on the IT side of the equation. Generally, IT project management reports to the CIO and, if the project has a large budget, then the CIO reports to the board. However, what about the management of and accountability for the 60 per cent of the costs and the delivery of the benefits on the business side of the equation? I agree with the statement often made that there is no such thing as an IT project - only business projects (see Fig 3). 


\section{Figure 3}

Business Project Management and Reporting

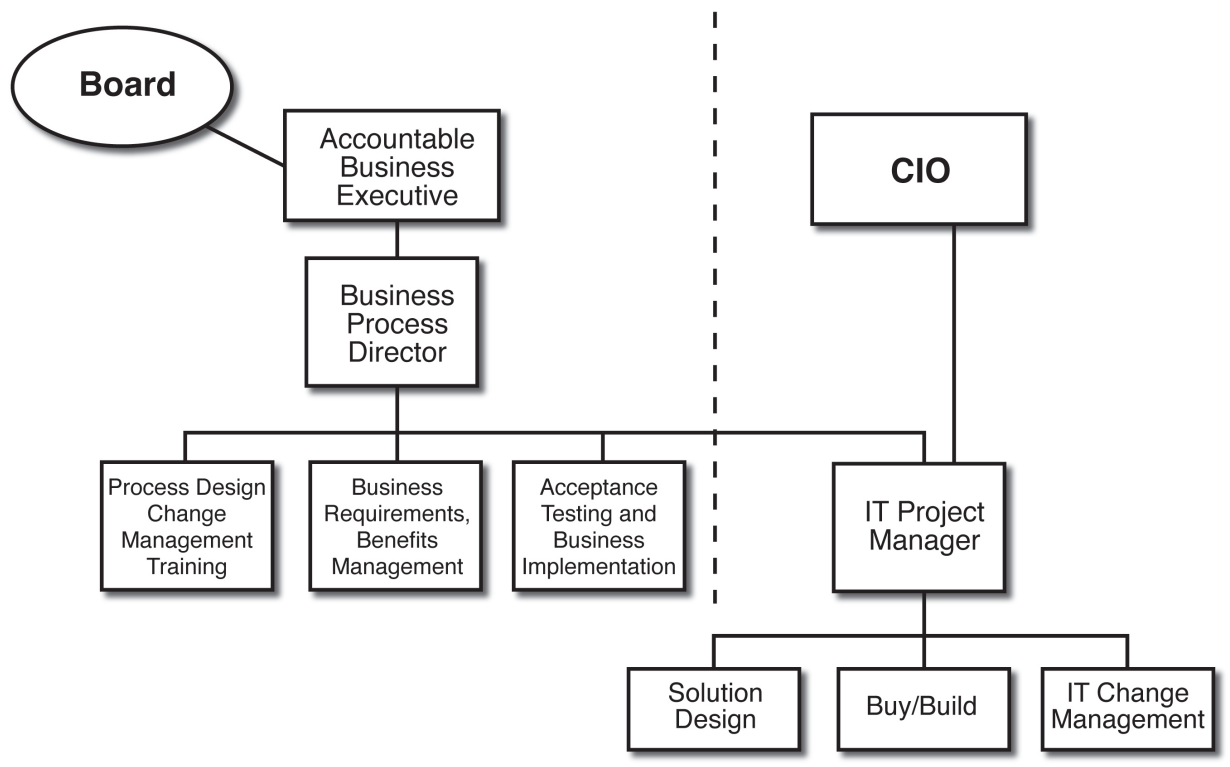

The Business is accountable for delivering the total project
The $\mathrm{CIO}$ is accountable for delivering the agreed IT solution to the business

Post mortems on failures tend to come up with common problems including:

- project alignment with strategic direction;

- poorly expressed business requirements;

- complete underestimation of the business effort and impact;

- untested benefits cases; and

- no plan or project to realise benefits.

All of these problems stem from one root cause: poor governance and organisation on the business side of the equation.

In too many organisations we see the IT project manager doing the job of the business project manager and making business decisions he or she is not qualified to make. As I pointed out before, IT will fill the vacuum to get the job done.

I suspect the rate of project failure would diminish significantly if IT project management disciplines were implemented on the business side of the equation and business took on the accountability for the proper business management of the overall project as described in the diagram above.

So why does not this happen? Why is not the obvious solution often implemented? 
I do not have a specific answer but here are three relevant observations:

1. Running projects is foreign to most business people and for the most part they are not rewarded for implementing a large business project, they are rewarded for achieving bottom line profits. Business management is put in a conflicting situation often short term (business profit) versus long term (sustainability and growth).

2. Taking people out of line roles to populate a project is an issue. Business managers accountable for the bottom line are loath to put their best staff into projects because the business suffers.

3. Generally a lack of business transformation skills in the business including process design and change management, the people who would effectively scope the strategic business project, and help business management understand what has to be done to achieve the desired outcomes - these people tend to be in IT.

\section{A word on the relationship between the board and IT - and IT projects}

Organisations that are heavily depend on IT or which have large organisational change and IT projects to deliver, do not have the bandwidth in the boardroom to exercise good governance.

Many organisations establish a board subcommittee for IT, similar to the audit and risk committee and this committee deals with specific IT governance including strategic alignment, prioritisation, approval, delivery, benefits, resourcing and the balancing of supply demand equation. Implementing an IT committee to the board is one way a board can realistically govern IT. And most importantly, it is necessary to ensure that business recognition and reward structures recognise business accountability for project and benefits delivery (see Fig 4). 


\section{Figure 4}

The relationship between the Board and IT ... and the Project
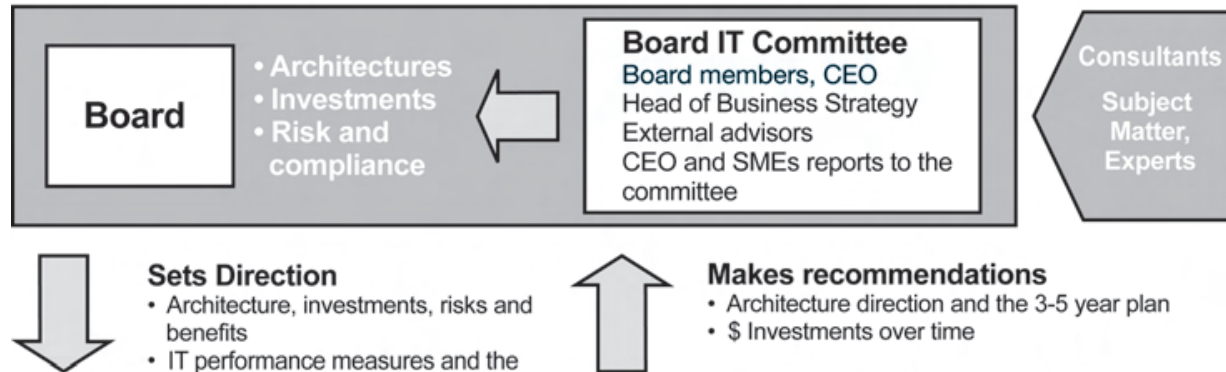

Sets Direction

- Architecture, investments, risks and benefits

- IT performance measures and the organisation to achieve from an organisation-wide perspective

- Monitors performance measuress

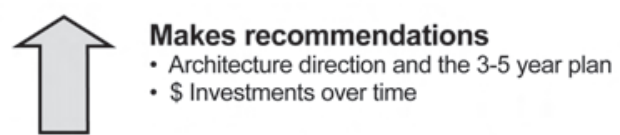

Reports on measures set by the Board

- Progress against the 3-5 year plan

- Major issues and risks

\section{CIO and the IT Team}

- Develops, maintains and delivers business aligned IT strategy and plans

- Delivers IT operations to business-driven

Service Level Agreements

- Monitors risk

Business Management

- Ensures business alignment to IT strategy and plans

- Prioritises projects, delivers and measures benefits

- Monitors Service Level Performance and risk

\section{Concluding remarks}

In summary the Board must:

- ensure that IT governance is understood and implemented across the organisation;

- differentiate between IT governance and IT Management;

- business management and executives own the management and outcomes of IT projects;

- insist on seeing clear and single point business accountability for strategic projects;

- monitor project risks, deliverables and outcomes rather than technical Gantt chart status reports; and

- ensure that business recognition and reward structures recognise business accountability for project and benefits delivery. 


\section{References}

Weill, Peter and Jeanne Ross (2004), IT Governance: How Top Performers Manage IT Decision Rights for Superior Results, Harvard Business School Press.

Broadbent, Marianne and Peter Weill, 'Effective IT Governance. By Design,' Gartner EXP Premier Report, January 2003.

\section{ENDNOTES}

1 The Sarbanes Oxley Act of 2002, also known as the Public Company Accounting Reform and Investor Protection Act of 2002 is a United States federal law passed in response to a number of major corporate and accounting scandals. For a more detailed explanation, see http://en.wikipedia.org/ wiki/Sarbanes-Oxley_Act.

2 See ASX Corporate Governance Principles at http://www.asx.com.au/supervision/ governance/ principles_good_corporate_governance.htm 